\title{
The sexual and reproductive health needs of youth in South Africa - history in context
}

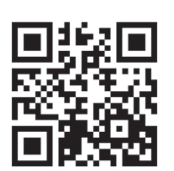

Adolescence is a time of rapid transition, of significant emotional, physical and psychological changes. These changes influence behaviour, in particular decisions to engage in risky behaviour, including sexual activity, alcohol consumption, smoking and taking drugs. Eighty-eight per cent of the 1.2 billion adolescents worldwide live in developing countries where access to sexual and reproductive health (SRH) services that could support them are often inadequate and fragmented. ${ }^{[1]}$ Unplanned pregnancies can affect the health and wellbeing of adolescents, placing them at risk for morbidity and mortality related to unsafe abortion and childbirth, as well as limiting their educational and employment opportunities.

South African (SA) youth continue to be vulnerable, with an HIV prevalence of 7.3\% reported for 15 - 24-year-olds in 2012. ${ }^{[2]}$ A survey conducted in 2007 in four of the nine SA provinces showed that $19.2 \%$ of females aged 12 - 19 years had had at least one pregnancy, the majority of which were unwanted, while $5.8 \%$ of males in the same age group had impregnated a girl. ${ }^{[3]}$ In addition, reported condom use by 15 - 24-year-olds in their most recent sexual encounter dropped from $85.2 \%$ to $67.5 \%$ for males and from $66.5 \%$ to $49.8 \%$ for females, according to two nationally representative surveys conducted in 2008 and 2012, respectively. ${ }^{[2]}$

In 2008, the Youth Risk Behaviour Survey showed 30\% of female learners reporting ever having had sex, with $24 \%$ reporting pregnancy. ${ }^{[4]}$ Fifteen per cent of the sexually active female learners reportedly did not usually use contraception, and $67 \%$ did not use condoms. ${ }^{[4]}$ In addition, $71 \%$ of the sexually active male learners did not use condoms, ${ }^{[4]}$ and of the $4.4 \%$ of sexually active learners who had had a sexually transmitted infection (STI), only half had received treatment. [5]

SA has a statutory commitment to address these problems, ${ }^{[5]}$ so the state of youth SRH has not been ignored. Many government and nongovernmental organisation (NGO) initiatives have been implemented since SA's transition to democracy, such as:

- Policies addressing youth SRH (Table 1)

- National media campaigns promoting awareness of HIV/AIDS among youth, e.g. the Soul City, Soul Buddyz and loveLife programmes

- Peer education programmes, e.g. Old Mutual's I Have Hope AIDS Peer Group Project (1993) and the Society for Family Health's Abasha Phezulu Peer Helper project (1993)

- Youth SRH service provision programmes, namely the National Adolescent Friendly Clinic Initiative (NAFCI) launched in 2001 and loveLife programmes

- HIV prevention awareness programmes, e.g. the Stepping Stones HIV prevention programme.
The current guiding policy for youth SRH initiatives is the 2012 Integrated School Health Policy (ISHP), which outlines SRH care for youth. This policy states that all learners in secondary schools should receive SRH counselling, particularly risk behaviour counselling. Dual-method contraception, HIV counselling and testing (HCT) and STI screening services are to be provided for sexually active learners by an on-site nurse or via referral to a healthcare facility offering the services. ${ }^{[5]}$ However, provision of SRH preventive services (namely contraception and condom provision) in schools has been contested ${ }^{[6]}$ in spite of the most recent youth HIV, STI and pregnancy statistics ${ }^{[4,5]}$ and the 2005 SA Children's Act (which enables youth aged $>12$ years to access SRH care services without parental consent and ensures confidentiality) $\cdot{ }^{[4]}$

\section{Government-level school health programmes}

In 1999, the Department of Education initiated the school health programme by establishing the National Policy on HIV and AIDS for Learners and Educators in Public Schools and Students and Educators in Further Education and Training Institutions. ${ }^{[7]}$ As a result, the HIV and AIDS Life Skills Education Programme was implemented in 2000 with the aim of reducing the vulnerability of young people to HIV and AIDS and enhancing their knowledge and skills for responsible sexual behaviour decisions. The programme was implemented through Life Orientation (LO) subjects across all grades; however, evaluation studies identified challenges to this programme, such as insufficient LO teachers and lack of integration into the schools' system and policies (among others). ${ }^{[7]}$

The 2003 National School Health Policy (NSHP) was then implemented as a health promotion and preventive school-based initiative for youth, integrating school and other district health services. Some of the problems identified with the implementation of the NSHP included low service provision, suboptimal and inequitable nurse-to-school ratios, and the absence of referral services to respond to problems identified via screening assessments. ${ }^{[5]}$

In 2009, the HIV and AIDS Life Skills Education Programme was revised, focusing among other things on risk behaviours such as unprotected sex and multiple concurrent sexual partners. Schoolbased support teams and school management teams were also established to aid implementation. ${ }^{[8]}$ The ISHP was put into effect in 2012 to address the problems experienced with the NSHP. It is overseen collaboratively by the National Department of Health (DoH), the Department of Basic Education and the Department of Social Development. Offering higher-level support and increasing the number of schools included in the programme, the ISHP is expected to extend the range of services previously offered by the NSHP. However, with the expansion of services, concerns 
regarding implementation, feasibility, effective service delivery and sustainability have been raised. ${ }^{[6]}$ The latest policy addressing youth SRH is the DoH's integrated strategy on HIV, STIs and tuberculosis (TB), 2012 - 2016, which was rolled out in 2013. ${ }^{[7]}$

\section{Research and evaluation of programmes and interventions}

Questions about the implementation and efficacy of the above policies have far-reaching implications with regard to the state of youth SRH. Although limited, research studies have evaluated some of the initiatives, and there are various reports on the effectiveness of different youth SRH interventions.

Three years after the loveLife programme was initiated, a baseline study in all SA provinces revealed no significant differences in HIV and STI prevalence between youth living in communities with loveLife youth centres and NAFCI interventions compared with those in communities with no interventions. ${ }^{[9]}$ It appeared that awareness or knowledge of youth interventions did not necessarily translate into engagement and/or behaviour change. However, a qualitative study on the NAFCI in the Greater Tzaneen subdistrict in Limpopo Province showed that adolescents used the NAFCI services at the clinic, especially contraception, STI and pregnancy services. Despite this, pregnancy and STI rates in the area did not decrease and HCT services were under-utilised. ${ }^{[10]}$

A cross-sectional nationally representative household survey showed that men and women who participated in at least one loveLife programme were significantly less likely to be infected with HIV than those who did not. ${ }^{[11]}$ Another cross-sectional populationbased household survey on 3123 youth (aged 18 - 24 years) in four SA provinces reported that multimedia exposure and not face-toface programme exposure was found to be protective against HIV infection. ${ }^{[12]}$

The Youth Friendly Services (YFS) programme, managed by loveLife between 1999 and 2006, was taken over by the DoH in 2006. It was estimated that the YFS programme was implemented in $70 \%$ of primary healthcare facilities by $2012 / 13 \cdot{ }^{[13]}$ However, interviews conducted in 2011 with healthcare workers in eight healthcare centres in Agincourt, Mpumalanga Province, suggested that these services were lacking and fell below the national estimates. ${ }^{[13]}$

An evaluation of 12 youth centres (under the loveLife programme, DoH centres and Youth and Adolescent Reproductive Health centres) was conducted nationally in 2001 among 1399 youth aged $12-24$ years and their parents. The survey showed that overall, while there was a fair degree of awareness of these centres, only $29 \%$ of youth visited the sites. ${ }^{[14]}$ Interestingly, centres offering recreational activities were busier than those providing SRH services only. Many of these centres have since ceased to function owing to lack of funding.
Overall, the evidence is that while several youth programmes have been implemented to address SRH, youth still face barriers when accessing this care.

The implementation of a school-based SRH model is discussed by Frolich et al. ${ }^{[15]}$ in this issue of SAMJ. The school programme was provided by the Centre for the AIDS Programme of Research in South Africa (CAPRISA) mobile services. This model was developed for high-school students in 14 schools in KwaZulu-Natal Province and comprised in-school SRH components. It included information giving and counselling together with HCT and referral to in-school services or standard public health sector services if required. ${ }^{[15]}$ The in-school services were provided by professional nurses from the study team and offered contraception including emergency contraception, HCT, syndromic management of STIs and pregnancy testing. In addition, referral was available for termination of pregnancy and HIV treatment and care. A counsellor was also available through a local NGO link who provided customised HCT incorporating counselling in relationships, negotiation around sex, high-risk sexual practices and assertive behaviour. These services were provided in the afternoon $(12 \mathrm{~h} 00-16 \mathrm{~h} 00)$ and therefore could be accessed after the school day. The services were rotated through the schools. The model was designed with input from an extensive community consultation and uptake was high. The important finding that few referrals to out-of-school services were taken up, even though the local DoH had been consulted about the programme, highlights the reluctance to attend local DoH facilities for SRH care demonstrated by adolescent learners. This is supported by studies that have shown that healthcare workers lack adolescentfriendly training or restrict services to adolescents younger than 16 years, ${ }^{[4]}$ and raises important concerns about whether these out-ofschool DoH- and NGO-driven services are acceptable, available and accessible, as it ultimately impacts upon service use by youth.

For long-term sustainability, the model implemented in the CAPRISA study would need to be adopted by the public sector, not only to provide the services but to ensure that the referral links with local facilities are youth friendly. Learners may lose interest and confidence in on-site services if they are unable or unwilling to attend standard services in their community. The model used in this study is aligned with the suggested model outlined in the ISHP, and the results suggest that the on-site approach is popular and acceptable to learners. However, the ISHP is also in the early stages of introduction, and though it is a good plan, it may be limited by resources in the public sector. As a follow-up to the CAPRISA study, we recommend that further research be undertaken to investigate how this on-site approach would be achieved if local public sector facilities could indeed spare staff to rotate through schools to provide services, and moreover provide

\author{
Table 1. Policies addressing youth SRH

\begin{tabular}{ll}
\hline 1999 & National Policy on HIV and AIDS for Learners and Educators in Public Schools and Students and Educators in Further \\
& Education and Training Institutions \\
2000 & National HIV and AIDS Life Skills Education Programme \\
2003 & National School Health Policy \\
2005 & South African Children's Act \\
2009 & Revised HIV and AIDS Life Skills Education Programme \\
2012 & Integrated School Health Policy \\
2013 & Department of Health's Integrated Strategy on HIV, STIs and TB, $2012-2016$ \\
SRH = sexual and reproductive health; STIs = sexually transmitted infections; TB = tuberculosis.
\end{tabular}


services after school hours for referral. This could be based on the existing mobile clinic approach, as equipment and consumables would be required to provide basic SRH services.

\section{Mags E Beksinska}

Maternal, Adolescent, and Child Health Research, Department of Obstetrics and Gynaecology, Faculty of Health Sciences, University of the Witwatersrand, Durban, South Africa, and Faculty of Epidemiology and Population Health, London School of Hygiene and Tropical Medicine, London, UK

mbeksinska@matchresearch.co.za

\section{Lavanya Pillay \\ Cecilia Milford}

Maternal, Adolescent, and Child Health Research, Department of Obstetrics and Gynaecology, Faculty of Health Sciences, University of the Witwatersrand, Durban, South Africa

\section{Jennifer A Smit}

Maternal, Adolescent, and Child Health Research, Department of Obstetrics and Gynaecology, Faculty of Health Sciences, University of the Witwatersrand, Durban, South Africa, and School of Pharmacy and Pharmacology, College of Health Sciences, University of KwaZulu-Natal, Durban

Corresponding author: M Beksinska (mbeksinska@matchresearch.co.za)
2. Shisana O, Rehle T, Simbayi LC, et al. South African National HIV Prevalence, Incidence and Behaviour Survey, 2012. Cape Town: HSRC Press, 2014:1-153.

3. Mchunu G, Peltzer $K$, Tutshana $B$, Seutlwadi L. Adolescent pregnancy and associated factors in South 3. Mchunu G, Peltzer K, eltshana B, Seutlwadi L. Adolescent pregnancy and associated facto
African youth. Afr Health Sci 2012;12(4):426-434. [http://dx.doi.org/10.4314/ahs.v12i4.5]

4. Holt K, Lince N, Hargey A, et al. Assessment of service availability and heath care workers' opinion Holt K, Lince N, Hargey A, et al. Assessment of service availability and heath care workers' opinions
about young women's sexual and reproductive health in Soweto, South Africa. Afr J Reprod Health about young womens $2012 ; 16(2): 283-294$

5. Department of Health and Department of Basic Education. Integrated School Health Policy 2012 . Department of Health and Department of Basic Education. Integrated School Health Policy 2012.
http://www.education.gov.za/Programmes/HealthPromotion/IntegratedSchoolHealthProgramme/ http://www.education.gov.Za/Programmes/HealthPromotion/IntegratedSchoolHealthProgramme/
tabid/870/Default.aspx on 09/07/2014 (accessed 9 July 2014). tabid/870/Default.aspx on 09/07/2014 (accessed 9 July 2014).

6. Shung-King M. From 'step-child of primary healthcare' to priority programme: Lessons for the implementation of the National Integrated School Health Policy in South Africa. S Afr Med 2013;103(12):895-898. [http://dx.doi.org/10.7196/SAMJ.7550]

7. Kumalo F, Panday S, Sithole S. The Department of Basic Education's Draft Integrated Strategy on HIV and AIDS, 2012-2016. South Africa: Department of Basic Education, 2011. http://www.education.gov. za/LinkClick.aspx?fileticket=S1OOfnrAuLs\%3d\&tabid=869\&mid=2451 (accessed 10 July 2014).

8. Panday S, Kumalo F, Dano A. Sexuality education - panacea for the prevention of HIV and AIDS amongst young people in schools? Presented at the $5^{\text {th }}$ SA AIDS Conference, Durban, 9 June 2011 http://www.education.gov.za/LinkClick.aspx?fileticket $=27$ cnozr3oVc\%3D\&tabid=93\&mid $=1722$ (accessed 10 July 2014)

9. Pettifor AE, Kleinschmidt I, Levin J, et al. A community-based study to examine the effect of a youth HIV prevention intervention on young people aged 15-24 in South Africa: Results of the baseline survey Trop Med Int Health 2005;10(10):971-980. [http://dx.doi.org/10.1111/j.1365-3156.2005.01483.x]

10. Baloyi GO. The evaluation of the national adolescent-friendly clinic initiative (NAFCI) programme in greater Tzaneen sub-district, Limpopo Province, South Africa. Master's dissertation. Pretoria University of South Africa, 2006. http://uir.unisa.ac.za/bitstream/handle/10500/1640/dissertation. pdf?sequence $=1$ (accessed 8 July 2014)

11. Pettifor AE, Rees HV, Kleinschmidt I, et al. Young people's sexual health in South Africa: HIV prevalence and sexual behaviours from a nationally representative household survey. AIDS 2005;19(14):1525-1534

12. Peltzer K, Ramlagan S, Chirinda W, Mlambo G, Mchunu G. A community-based study to examine the effect of a youth HIV prevention programme in South Africa. Int J STD AIDS 2012;23(9):653-658. [http://dx.doi.org/10.1258/ijsa.2012.011457]

13. Geary RS, Gomez-Olive FX, Kahn K, Tollman S, Norris SA. Barriers to and facilitators of the provision of a youth-friendly health services programme in rural South Africa. BMC Health Serv Res 2014;14(259):1-8. [http://dx.doi.org/10.1186/1472-6963-14-259]

14. Erulkar AS, Beskinska M, Cebekhulu Q. An assessment of youth centres in South Africa, 2001. http:// pdf.usaid.gov/pdf_docs/PNACN848.pdf (accessed 27 July 2014)

15. Frolich JA, Mkhize N, Dellar RC, Mahlase G, Montague C, Abdool Karim Q. Meeting the sexual and reproductive health needs of high school students in South Africa: Experiences from rural KwaZuluNatal. S Afr Med J 2014;104(10):687-690. [http://dx.doi.org/10.7196/SAMJ.7841]

Afr Med J 2014;104(10):676-678. DOI:10.7196/SAMJ.8809 